Document downloaded from:

http://hdl.handle.net/10251/48058

This paper must be cited as:

Palomares Gimeno, AE.; Franch Martí, C.; Ribera, A.; Abellán, G. (2012). NOx selective catalytic reduction at high temperatures with mixed oxides derived from layered double hydroxides. Catalysis Today. 191(1):47-51. doi:10.1016/j.cattod.2012.01.023.

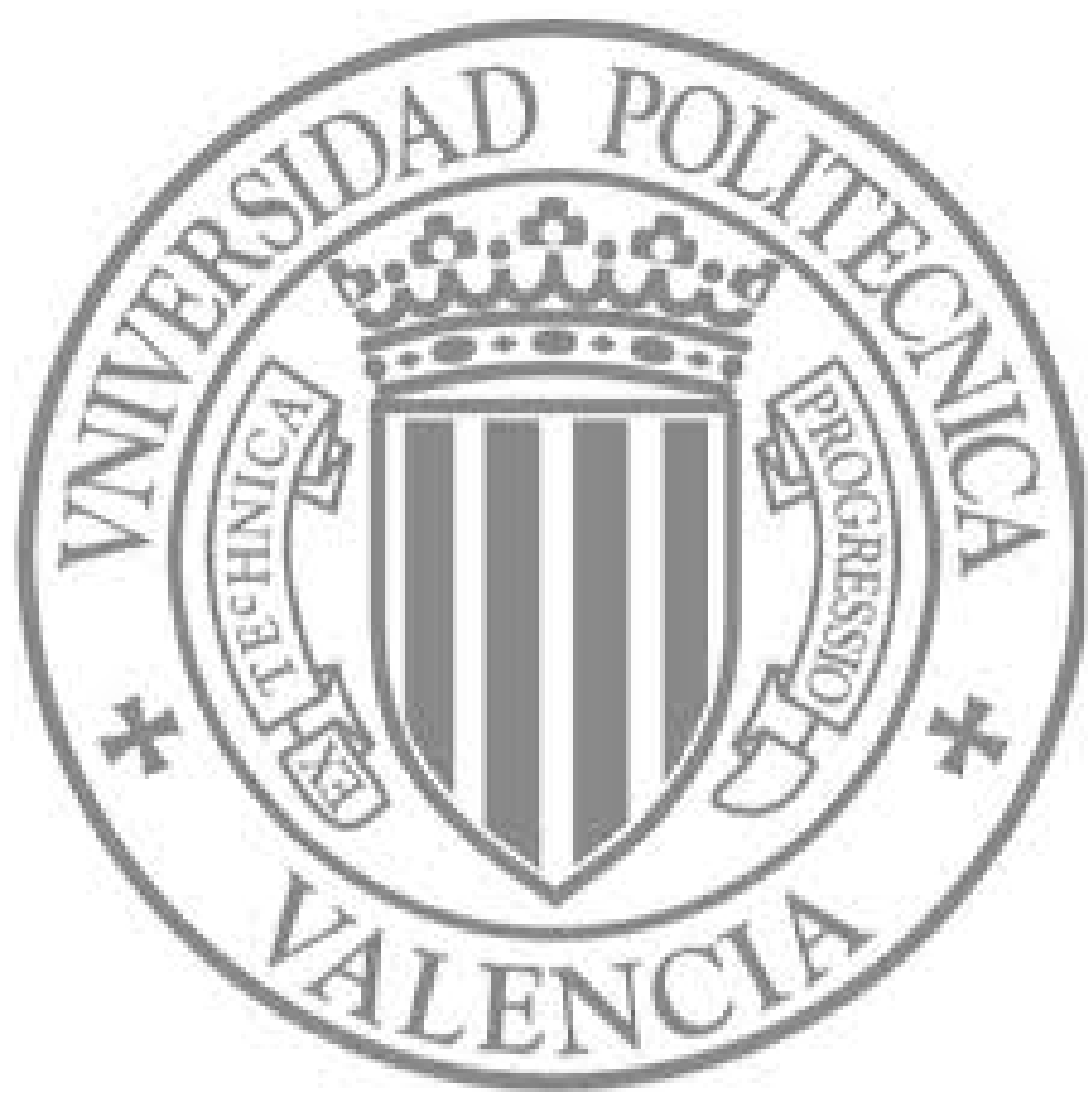

The final publication is available at

Copyright Elsevier 


\title{
NOX SELECTIVE CATALYTIC REDUCTION AT HIGH TEMPERATURES WITH MIXED OXIDES DERIVED FROM LAYERED DOUBLE HYDROXIDES
}

\author{
A. E. Palomares*, C. Franch, A. Ribera ${ }^{\dagger}$ and G. Abellán ${ }^{\dagger}$ \\ Instituto de Tecnologia Quimica, UPV-CSIC, Universidad Politecnica de Valencia, Avenida de los Naranjos s $/ n$. \\ 46022-Valencia (Spain), phone 34-6-3877800, fax 34-96-387780, email: apalomar@iqn.upv.es. \\ ${ }^{+}$Instituto de Ciencia Molecular, Universidad de Valencia, Catedrático José Beltrán 2, E46980, Paterna \\ (Valencia), Spain. Fax: (+34) 963543273
}

Keywords: $\mathrm{NO}_{\mathrm{x}}$, FCC, Layered Double Hydroxides, mixed oxides

* Author to whom correspondence should be addressed 
Abstract

Mixed oxides derived from Layered Double Hydroxides (LDHs) have been investigated as potential catalysts for the $\mathrm{NO}_{\mathrm{x}}$ removal at high temperatures. The best results were obtained with Co-Al mixed oxides derived from $\mathrm{LDHs}$ that are active at $750^{\circ} \mathrm{C}$ in the presence of oxygen and water. These catalysts could reduce or/and decompose the $\mathrm{NO}_{\mathrm{x}}$ formed in the dense phase of the FCC regenerator, being deactivated at oxygen concentrations higher than $1.5 \%$. Nevertheless this deactivation is not permanent and they would be regenerated after reduction with hydrogen at $530^{\circ} \mathrm{C}$. The influence of the layered double hydroxides (LDHs) preparation method on the catalyst activity was studied, observing that the activity of the catalyst depends on its chemical composition but it does not depend on the initial LDHs crystallinity, obtaining similar results independently of the synthesis method. 


\section{Introduction}

Nitrogen oxides are some of the most important air pollutants. The data from the Annual European Union LRTAP Convention emission inventory report show that in $2009,9233.5 \mathrm{Gg}$ of $\mathrm{NO}_{\mathrm{x}}$ were emitted in the EU-27. The $\mathrm{NO}_{\mathrm{x}}$ emissions in the European Union have decreased by almost $40 \%$ since 1990, but they are projected to be 6 percent above the aggregated Member State ceilings and 16 percent above the stricter ceiling for the European Community as a whole set for 2010. Current regulations controlling such pollution are becoming more stringent and new processes to control these pollutants are imperative [1-3].

In the FCC riser, around 50\% of the nitrogen-compounds present in the feed are converted into ammonium, while the more basic ones remain in the feed or end up in the coke formed on the catalyst during the cracking reaction. In the FCC regenerator, the coke is burnt off in the presence of oxygen producing nitrogen oxides. These emissions represent $50 \%$ of the total $\mathrm{NO}_{\mathrm{x}}$ emissions of the refinery [3-4], therefore, the amount of the $\mathrm{NO}_{\mathrm{x}}$ emitted from a FCC unit should be controlled. The use of additives that catalyze the NO reduction or decomposition in the FCC regenerator unit is probably the most simple and cost-effective method. Nevertheless these additives must be able to operate at the high temperatures found in the FCC regenerator (around $700-750^{\circ} \mathrm{C}$ ), and in the presence of other gases such as $\mathrm{CO}, \mathrm{SO}_{2}, \mathrm{CO}_{2}$, hydrocarbons, $\mathrm{O}_{2}$ and $\mathrm{H}_{2} \mathrm{O}$ [5-6]. In these conditions, the common catalysts used for the $\mathrm{NO}_{\mathrm{x}}$ selective catalytic reduction or decomposition such as metal exchanged zeolites [7], modified pillared clays [8] or promoted V catalysts [9-11] are not stable enough and other alternatives should be explored. In this way, additives based on Rh or Ir [2, 12-13], some derivatives of MCM-36 [14] and CuCe-Al complex oxides [15-16], have been proposed as active materials for the $\mathrm{NO}_{\mathrm{x}}$ removal in the FCC units showing interesting results. Also, $\mathrm{Mg}$-Al mixed oxides produced from layered 
double hydroxides (LDHs) are active catalysts for the simultaneous removal of $\mathrm{NO}_{\mathrm{x}}$ and $\mathrm{SO}_{2}$ in the FCC $[6,17]$, nevertheless more active materials are necessary.

LDHs are usually prepared by a coprecipitation method [18], mixing an aqueous solution of the metal salts and a $\mathrm{NaOH}$ solution, while maintaining the $\mathrm{pH}$ constant in an alkaline value. Nevertheless, this method leads to poorly crystallized solids. Recently, LDHs exhibiting a uniform size and well-defined hexagonal shape have been prepared by the so-called homogeneous precipitation methods [19-20]. In such methods, the ammonia generated by the hydrolysis of ammonia releasing reagents (ARRs), such as urea and hexamethylenetetramine (HMT), makes possible a slow increase of the media $\mathrm{pH}$, inducing a slow precipitation of the resulting LDH. This allows the formation of samples with a high crystallinity and with welldefined hexagonal-shaped particles.

The aim of this work is to prepare and to study the activity of different solids derived from LDHs prepared by different methods for the $\mathrm{NO}_{\mathrm{x}}$ removal at high temperature, in similar conditions to those found in the FCC unit regenerator.

\section{Experimental}

The catalysts used in the experiments are based in LDHs with different composition and prepared by different methods. Some Co-Al, Ni-Cr and Mn-V LDHs were prepared by the coprecipitation method and some $\mathrm{Co}-\mathrm{Al}$ and $\mathrm{Ni}-\mathrm{Cr} \mathrm{LDHs}$ were prepared by the homogeneous precipitation method. In order to compare the different samples, the $\mathrm{M}^{\mathrm{II}} / \mathrm{M}^{\mathrm{III}}$ metal ratio was kept constant at the value of 2 .

The samples prepared by the coprecipitation method were made by mixing two solutions (a $\mathrm{M}^{\mathrm{II}}$ and $\mathrm{M}^{\mathrm{III}} 1 \mathrm{M}$ solution and a $\mathrm{NaOH}$ and $\mathrm{NaNO}_{3} 1 \mathrm{M}$ solution), drop wise, while stirring at room temperature. The $\mathrm{pH}$ was kept constant at a value of 8 for the Co-Al sample and at 6 for the Ni-Cr LDH system. The resulting slurry was aged at $80^{\circ} \mathrm{C}$ for four days and filtered and 
washed with distilled water until the absence of nitrates. The manipulations were carried out in an inert atmosphere in order to avoid the sample contamination by carbonate anions.

Other Co-Al and Ni-Cr LDHs with the same chemical composition were prepared by the homogeneous precipitation method using urea or hexamethylenetetramine (HMT) as ammonia releasing reagent (ARR). The samples prepared by the homogenous precipitation method with urea as ARR, were made by mixing $50 \mathrm{~mL}$ of a metal cation solution $(20 \mathrm{mM}$ concentration) with $50 \mathrm{~mL}$ of a urea solution $(35 \mathrm{mM}$ concentration). The synthesis was carried out in a two-neck flask (equipped with a reflux condenser) with a nitrogen flow. The mixed solution was heated at $97{ }^{\circ} \mathrm{C}$ with a continuous magnetic stirring for 2 days. The resulting slurry was filtered, washed with deionized water and anhydrous ethanol and dried.

A Ni-Cr LDH was made by the homogeneous precipitation method using HMT as ammonia releasing reagent. A solution of nickel chloride and chromium chloride, with a total metal cation concentration of $0.15 \mathrm{M}$, was prepared and the HMT was added. The added HMT amount was three times that of the $\mathrm{Cr}^{3+}$. The resulting mixture was introduced into a Teflon inner vessel with a stainless steel outer vessel. The vessels were placed in a preheated oven at $140{ }^{\circ} \mathrm{C}$, and the mixture reacted under airtight conditions. After $72 \mathrm{~h}$, the vessels were cooled to room temperature. The resulting product was filtered, washed with deionized water and anhydrous ethanol and dried.

The samples were characterized by X-ray powder diffraction profiles, collected with a Siemens d-500 X-ray diffractometer $(\mathrm{Cu}-\mathrm{K} \alpha$ radiation, $\lambda \alpha=1.54184 \AA$ ) at $293(2) \mathrm{K}$. Typically, profiles were collected as step scans over a $2.16 \mathrm{~h}$ period in the $5^{\circ}<2 \Theta<70^{\circ}$ range with a step size of $0.05^{\circ}$. Thermogravimetric measurements were carried out, in order to determine the water amount, with a Mettler Toledo TGA/SDTA 851 apparatus in the 25-800 ${ }^{\circ} \mathrm{C}$ temperature interval under air and at $5 \mathrm{~K} \cdot \mathrm{min}^{-1}$ scan rate. Metallic composition of bulk 
samples was determined by electron probe microanalysis performed in a Philips SEM XL30 equipped with an EDAX microprobe. Particle morphologies were studied with a Hitachi S4100 scanning electron microscope at an accelerating voltage of $20 \mathrm{keV}$.

The catalytic experiments were carried out in a fixed bed quartz reactor. Prior to reaction, the catalyst was activated under $\mathrm{H}_{2}$ at $530^{\circ} \mathrm{C}$ for 30 minutes. The $\mathrm{H}_{2}$ was flushed out with $\mathrm{N}_{2}$ and the catalyst brought from this temperature to the reaction temperature $\left(750^{\circ} \mathrm{C}\right)$ under $\mathrm{N}_{2}$. In the reaction $1 \mathrm{~g}$ of the calcined catalyst was placed into a quartz reactor and a gas with $900 \mathrm{ppm}$ NO, 840 ppm $\mathrm{C}_{3} \mathrm{H}_{8}$, different oxygen concentration and nitrogen, as carrier gas, was introduced in the reactor, using a total flow of $650 \mathrm{~cm}^{3} \cdot \mathrm{min}^{-1}$. These reaction conditions simulate those of the FCC regenerator except for the presence of propane instead of $\mathrm{CO}$. This was made for security reasons, but previous experiments made in our laboratory have shown that in these conditions the tested catalysts present a similar behavior with both reducing agents. The outlet stream was analyzed by a chemiluminiscence analyzer, model Rosemount $951 \mathrm{~A}$.

\section{Results and Discussion}

The X-ray diffractograms of the samples (Figure 1) show only the typical peaks of the LDH phase. They present sharp intense peaks at low theta values and less intense peaks at higher angular values. These peaks were indexed by assuming a rhombohedral structure, 6R symmetry. The indexation of the peaks (001) allows the determination of the basal spacing in each case. There is a shift in the lower angle peaks when comparing the samples prepared by the coprecipitation method with the samples prepared by the homogeneous method. This shift is related to the different size of the different interlayer anions present in both samples. Carbonates are the anions present in the samples prepared by the homogeneous method and nitrates are the anions present in the samples prepared by the coprecipitation method. Taking into account that the Van der Waals thickness of the brucite sheets is ca. $4.7 \AA$, the calculated 
basal spacing indicates a gallery height of ca. $3.1 \AA$ for the samples prepared by the homogeneous method and $4.2 \AA$ for the samples prepared by the coprecipitation method. These values are in good agreement with the values commonly accepted for the basal spacing of carbonate and nitrate LDH systems that are $7.8 \AA$ and $8.49 \AA$ respectively. Moreover, taking into account the XRD profiles shown in the figure 1, it should be pointed out that the samples prepared by the homogeneous precipitation method present sharper intense peaks than the samples prepared by the coprecipitation method. This is due to the ARR decomposition that gradually increases the synthesis gel $\mathrm{pH}$, producing a LDH material with a high crystallinity and with well-defined hexagonal-shaped particles as it can be observed by scanning electron microscopy (Figure 2).

Metallic atomic composition of the samples was determined by electron probe microanalysis. Table 1 shows the metal ratio in the synthetic gel (theoretical) together with that found in the isolated materials. Furthermore, the thermogravimetric analyses of the samples allow us to determine their water content and to establish the formulae for each material (Table 1). As it can be seen, there is a good agreement in all cases of the experimental and the theoretical data.

The activity of the different catalysts was tested at $750^{\circ} \mathrm{C}$ with different oxygen concentrations, simulating the conditions of the FCC regenerator. At this temperature LDHs form mixed oxides [6] and as it can be seen in Figure 3, all the mixed oxides derived from LDH are active in the absence of oxygen. Nevertheless, an increase in the oxygen concentration causes a deactivation of the catalysts. The deactivation rate depends on the catalyst composition. In this way, the catalyst based in $\mathrm{Mn}-\mathrm{V}$ shows the worst results, starting its deactivation even in the absence of oxygen. This indicates that this material is not adequate for the removal of $\mathrm{NO}_{\mathrm{x}}$ at high temperature. These results agree with those previously described in literature showing that V- 
catalysts are quite active at temperatures between $250-450^{\circ} \mathrm{C}[9,10]$ but its activity dramatically decrease at temperatures above $500^{\circ} \mathrm{C}$, probably because the vanadium volatility at high temperatures results in the catalyst deactivation.

Some better results were obtained with the $\mathrm{Co}-\mathrm{Al}$ and $\mathrm{Ni}-\mathrm{Cr}$ mixed oxides derived from $\mathrm{LDHs}$. These catalysts are active even in presence of $1 \%$ oxygen, being the $\mathrm{Ni}-\mathrm{Cr}$ catalyst the most stable catalyst up to $1 \%$ oxygen concentration. A further increase in the oxygen concentration results in a fast deactivation of the $\mathrm{Ni}-\mathrm{Cr}$ catalyst but in a very smooth deactivation of the $\mathrm{Co}-\mathrm{Al}$ catalyst. These results are very interesting, because the most desirable catalysts for the $\mathrm{NO}_{\mathrm{x}}$ removal in a FCC unit are those that can be active in the presence of up to $1 \%$ oxygen concentration, which is the oxygen concentration found in the dense phase of the FCC regeneration unit.

The influence of the catalyst synthesis method on the catalyst activity was studied by preparing different $\mathrm{Co}-\mathrm{Al}$ and $\mathrm{Ni}-\mathrm{Cr}$ catalysts by the different methods described in the experimental part and testing their activity. As it was discussed, the different synthesis methods lead to the formation of LDHs with different crystallinity. The results obtained with the Ni-Cr catalysts prepared by different methods are shown in Figure 4 and as it can be seen they are quite similar. The only difference that can be observed is a faster deactivation of the catalyst prepared with urea at low oxygen content. Nevertheless, at higher oxygen concentration (1.5\%) the catalytic behavior of all the catalysts is the same. The same results were obtained with the Co-Al catalysts prepared by different methods. These results indicate that the catalyst activity is determined by its chemical composition and it does not depend on the crystallinity of the original LDH sample or on the preparation method. This can be related to the formation of the mixed oxides from the LDHs that occur at the reaction temperature. As it can be seen in the $\mathrm{XRD}$ of the samples after reaction (Figure 5) the $\mathrm{Co}-\mathrm{Al}$ samples form a cobalt spinel $\left(\mathrm{Co}_{3} \mathrm{O}_{4}\right.$ 
and/or $\mathrm{CoAl}_{2} \mathrm{O}_{4}$ ) during the reaction and the $\mathrm{Ni}-\mathrm{Cr}$ samples form a mixture of $\mathrm{NiO}$ and $\mathrm{Cr}_{2} \mathrm{O}_{3}$. The formation of these new phases depends only on the catalyst composition but it does not depend on the initial LDHs crystallinity, yielding similar results with all the catalysts independently of the synthesis method used.

The activity of the Co-Al catalyst was tested in the presence of water (Figure 6), observing that in contrast with the results obtained in the absence of water, there is a better activity of the catalyst in the presence of water at low oxygen content. Nevertheless in the presence of $1.5 \%$ of oxygen, the water accelerates the catalyst deactivation. It should be pointed out, that this deactivation is not permanent and the additive will recover the initial activity after its reduction with hydrogen at $530^{\circ} \mathrm{C}$.

\section{Conclusions}

The results obtained show that it is possible to remove $\mathrm{NO}_{\mathrm{x}}$ at high temperature using $\mathrm{Co}-\mathrm{Al}$ or $\mathrm{Ni}-\mathrm{Cr}$ mixed oxides derived from LDHs. The Co-Al catalysts are active even in the presence of $1.5 \%$ of oxygen and in the presence of water, which are the typical conditions found in the dense phase of the FCCU regenerator. At the reaction temperature the $\mathrm{Co}-\mathrm{Al} \mathrm{LDH}$ forms a cobalt spinel $\left(\mathrm{Co}_{3} \mathrm{O}_{4}\right.$ and/or $\left.\mathrm{CoAl}_{2} \mathrm{O}_{4}\right)$ and its activity depends on the chemical composition, but it does not depend on the initial LDHs crystallinity. Similar catalytic results are obtained independently of the synthesis method employed.

\section{$\underline{\text { Acknowledgements }}$}

A.E. Palomares and C. Franch thank the Spanish Government (projects MAT2009-14528C02-01 and CONSOLIDER INGENIO 2010) and the European Union (European Community's Seventh Framework Programme FP7/2007-2013 under Grant Agreement No. 226347 Project) for financial support. A. Ribera and G. Abellan acknowledge financial 
support from the Spanish Ministerio de Ciencia e Innovación with FEDER co-financing (CTQ-2008-06720) and the Generalitat Valenciana (Prometeo Program).

\section{References}

[1] W.C. Cheng, G. Kim, A.W. Peters, X. Zhao, K. Rajagopalan, M.S. Zierbath and C.J. Pereira, Catal. Rev. - Sci. Eng. 40 (1998) 39.

[2] E.F. Iliopoulou, E.A. Efthimiadis, I.A. Vasalos, J.-O. Barth and J.A. Lercher, Appl. Catal. B 47 (2004) 165.

[3] I.V.Babich, K. Seshan and L. Lefferts, Appl. Catal. B 59 (2005) 205.

[4] K.L. Dishman, P.K. Doolin and L. D. Tullock, Ind. Eng. Chem. Res. 37 (1998) 4631.

[5] R.H. Harding, A.W. Peters and J.R.D. Nee, Appl. Catal. A 221 (2001) 389.

[6] A. Corma, A.E. Palomares, F. Rey and F. Márquez, J. Catal. 170 (1997) 140.

[7] A. E. Palomares, C. Franch, A. Corma, Catal. Today 172 (1) (2011) 90.

[8] L. Chmielarz, P. Kustrowski, R. Dziembaj, P. Cool, E.F. Vansant, Catal. Today 119 (2007) 181.

[9] P. Forzatti, Appl. Catal. A 222 (2001) 221.

[10] J. Banas, V.Tomasic, A. Weselucha-Birczynska, M. Najbar, Catal. Today 119 (2007) 199.

[11] A. Adamski, B.Gil, S. Zojka, Catal. Today 137 (2008) 292.

[12] E.F. Iliopoulou, E.A. Efthimiadis, L. Nalbandian, I.A. Vasalos, J.-O. Barth and J.A. Lercher, Appl. Catal. B 60 (2005) 277.

[13] E.F. Iliopoulou, E.A. Efthimiadis, A.A. Lappas, D.K. Iatridis and I.A. Vasalos, Ind Eng. Chem. Res. 43 (2004) 7476.

[14] J.O.Barth, A. Jentys, E.F. Iliopoulou, I.A. Vasalos and J.A. Lercher, J. Catal. 227 (2004) 117. 
[15] B. He and M. He, Appl. Catal. B 37 (2002) 75.

[16] A.E. Palomares, A. Uzcategui, A.Corma, Top. Catal. 52 (2009) 1060.

[17] A. E. Palomares, J.M. López-Nieto, F.J. Lázaro, A. López and A. Corma, Appl. Catal. B $20(4)(1999) 257$.

[18] S. Miyata, Clays Clay Miner. 28 (1980), 50.

[19] L. Li, R. Ma, Y. Ebina, N. Iyi, T. Sasaki, Chem. Mater. 17 (2005) 4386.

[20] J.J. Almansa, E. Coronado, C. Martí-Gastaldo, A. Ribera, Eur. J. Inorg. Chem. (2008) 5642. 


\section{Caption to figures}

Figure 1. XRD of the Co-Al and Ni-Cr LDHs catalysts prepared by the (A) coprecipitation method and by the (B) homogeneous precipitation method.

Figure 2. SEM image of the Co-Al LDH sample prepared by the homogeneous precipitation method using urea as ARR.

Figure 3. Activity for the $\mathrm{NO}_{\mathrm{x}}$ removal at $750^{\circ} \mathrm{C}$, with different oxygen contents, of the (A) Mn$\mathrm{V}$, (B) Ni-Cr and (C) $\mathrm{Co}-\mathrm{Al}$ mixed oxides derived from $\mathrm{LDHs}$ prepared by the coprecipitation method.

Figure 4. Activity for the $\mathrm{NO}_{\mathrm{x}}$ removal at $750^{\circ} \mathrm{C}$, with different oxygen concentration, of $\mathrm{Ni}-\mathrm{Cr}$ catalysts prepared by (A) homogeneous precipitation with urea (B) homogeneous precipitation with HMT and (C) coprecipitation.

Figure 5. XRD, after reaction, of the (A) Co-Al and (B) Ni-Cr mixed oxides derived from the LDHs samples prepared by the coprecipitation method and by the homogeneous precipitation method.

Figure 6. Activity of the Co-Al catalyst prepared by the coprecipitation method for the $\mathrm{NO}_{\mathrm{x}}$ removal at $750^{\circ} \mathrm{C}$, with different oxygen concentration, in the presence $(2.5 \%)$ and in the absence of water, 
Table 1. Metal ratio of the synthetic gels (theoretical) and the bulk isolated compounds (experimental) estimated from Electronic Probe Microanalysis, water content determined from the thermogravimetric analysis and corresponding calculated molecular formulae.

\begin{tabular}{lccccc}
\hline & \multicolumn{3}{c}{$x^{\text {[a] }}$} & \multicolumn{3}{c}{ Water content } & Molecular formula \\
& Theor. & Exp. & Wt. \% & Mol. & \\
\hline CoAl-Copre & 0.33 & 0.35 & 6.35 & 110.5 & {$\left[\mathrm{Co}_{0.65} \mathrm{Al}_{0.35}(\mathrm{OH})_{2}\right]\left(\mathrm{NO}_{3}\right)_{0.350} \bullet 0.39 \mathrm{H}_{2} \mathrm{O}$} \\
CoAl-Urea & 0.33 & 0.34 & 7.57 & 99.8 & {$\left[\mathrm{Co}_{0.66} \mathrm{Al}_{0.34}(\mathrm{OH})_{2}\right]\left(\mathrm{CO}_{3}\right)_{0.170} \bullet 0.42 \mathrm{H}_{2} \mathrm{O}$} \\
NiCr-Copre & 0.33 & 0.33 & 5.08 & 116.9 & {$\left[\mathrm{Ni}_{0.67} \mathrm{Cr}_{0.33}(\mathrm{OH})_{2}\right]\left(\mathrm{NO}_{3}\right)_{0.330} \bullet 0.33 \mathrm{H}_{2} \mathrm{O}$} \\
NiCr-Urea & 0.33 & 0.34 & 5.73 & 106.8 & {$\left[\mathrm{Ni}_{0.66} \mathrm{Cr}_{0.34}(\mathrm{OH})_{2}\right]\left(\mathrm{CO}_{3}\right)_{0.170} \bullet 0.34 \mathrm{H}_{2} \mathrm{O}$} \\
NiCr-HMT & 0.33 & 0.33 & 5.27 & 105.7 & {$\left[\mathrm{Ni}_{0.67} \mathrm{Cr}_{0.33}(\mathrm{OH})_{2}\right]\left(\mathrm{CO}_{3}\right)_{0.165} \bullet 0.31 \mathrm{H}_{2} \mathrm{O}$} \\
\hline
\end{tabular}

$[\mathrm{a}] x=\left[\mathrm{M}^{3+}\right] /\left(\left[\mathrm{M}^{2+}\right]+\left[\mathrm{M}^{3+}\right]\right)$ 

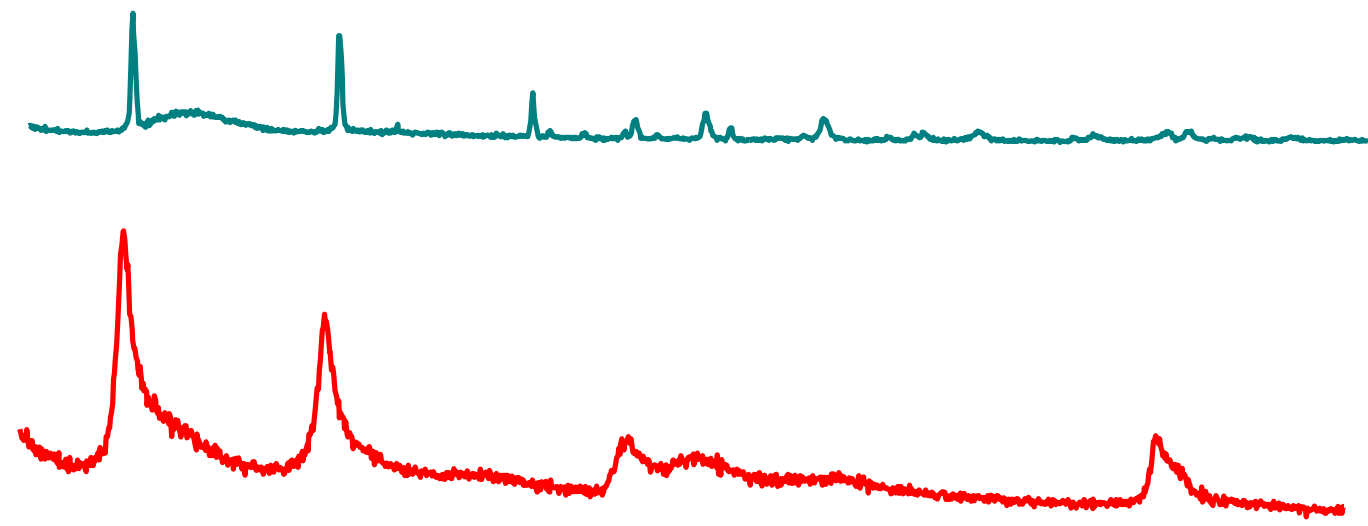

NiCr-Copre

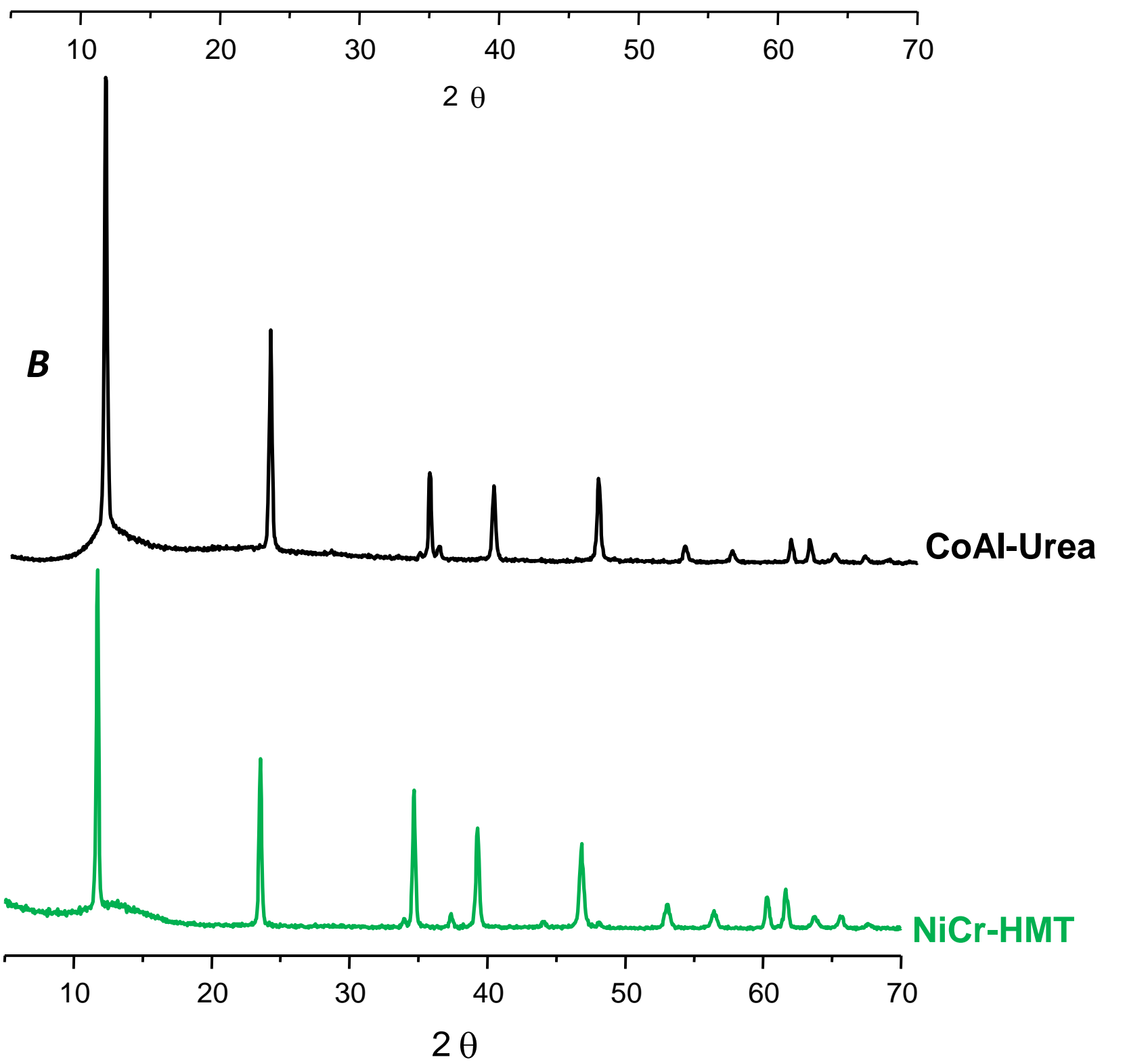




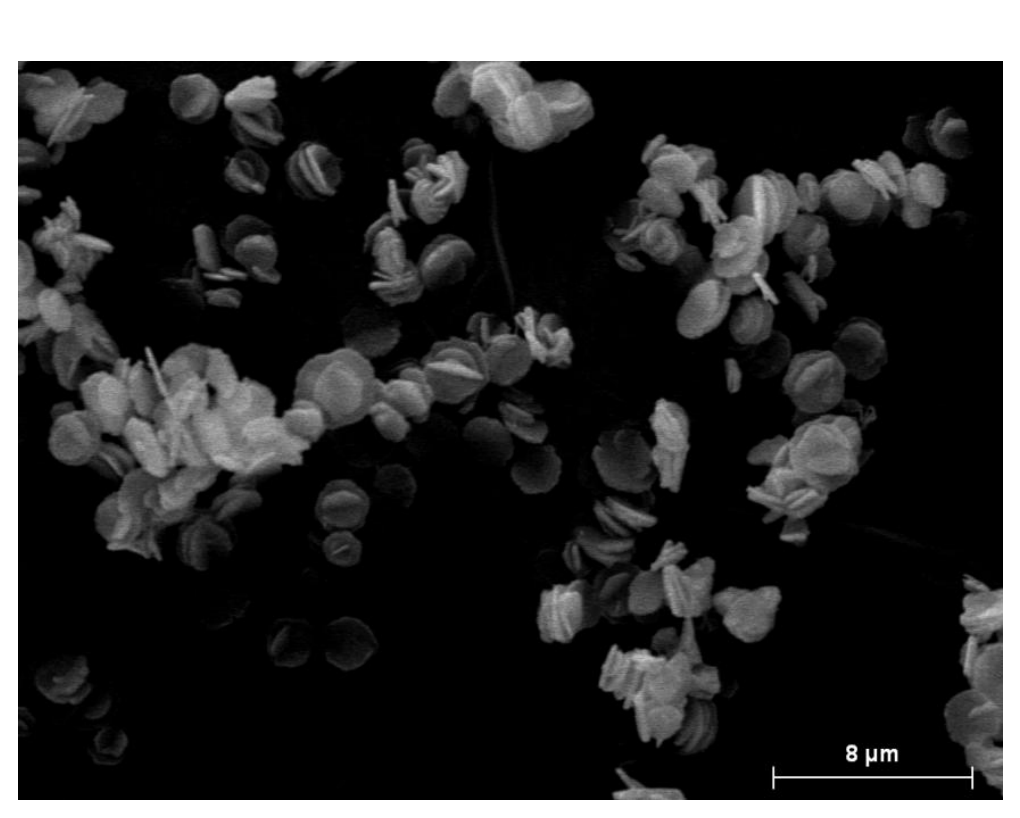

Figure 2

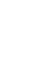

.
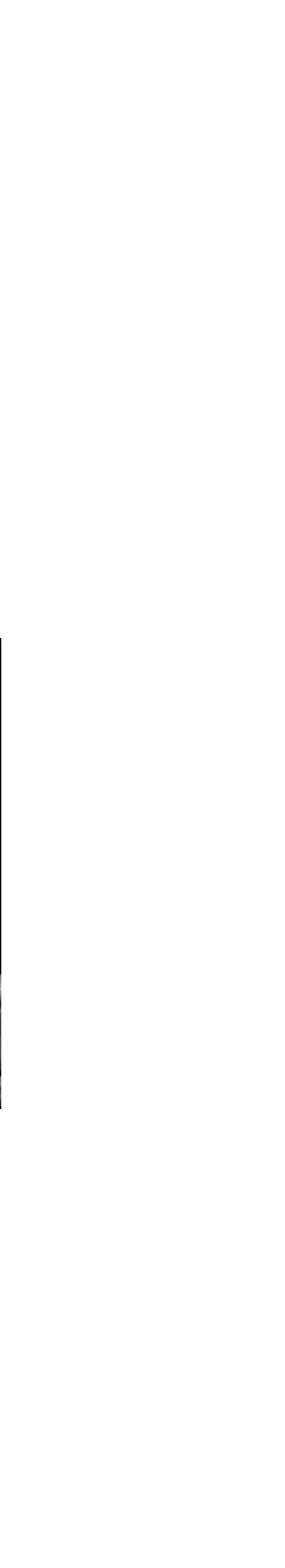


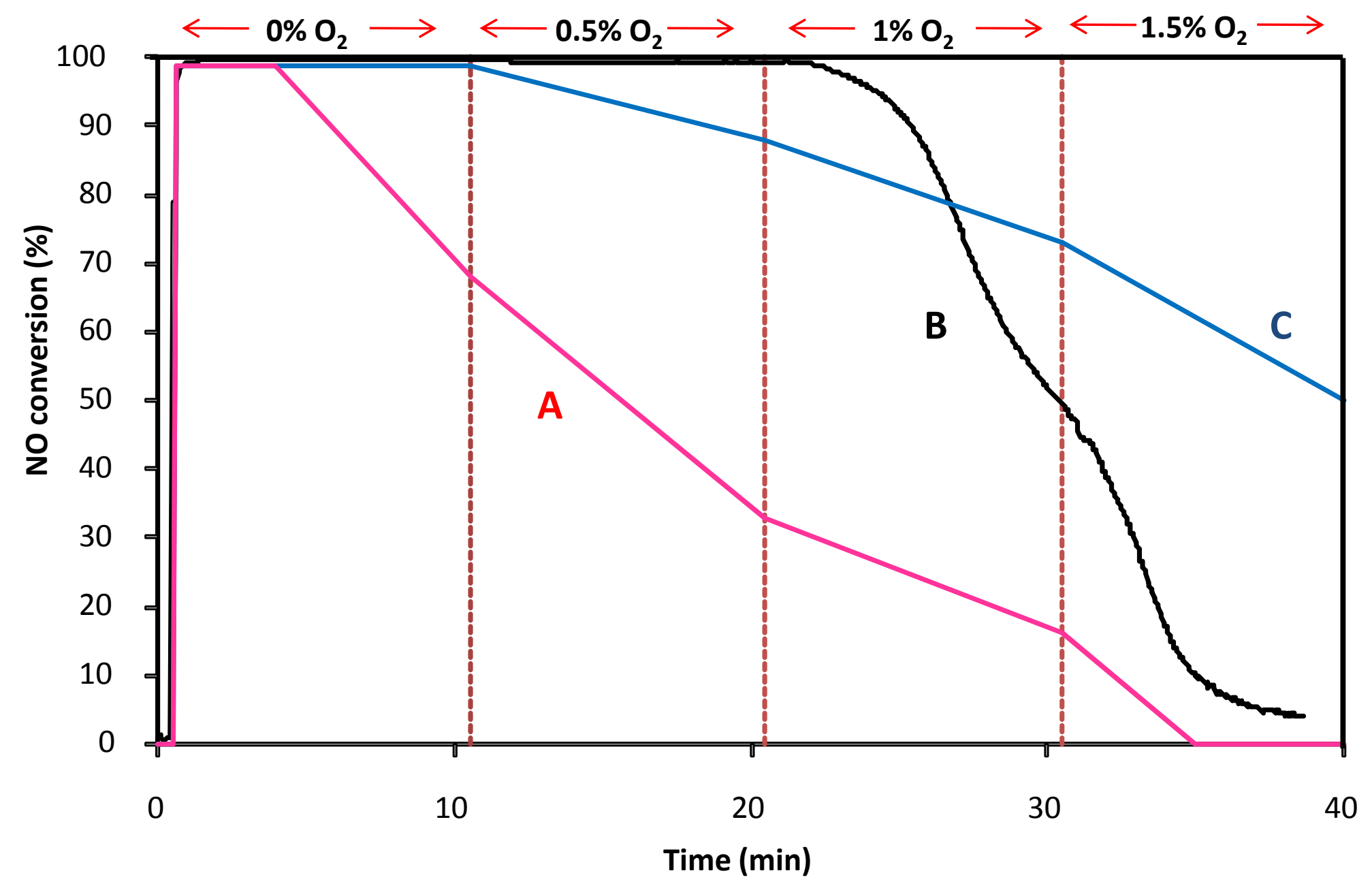




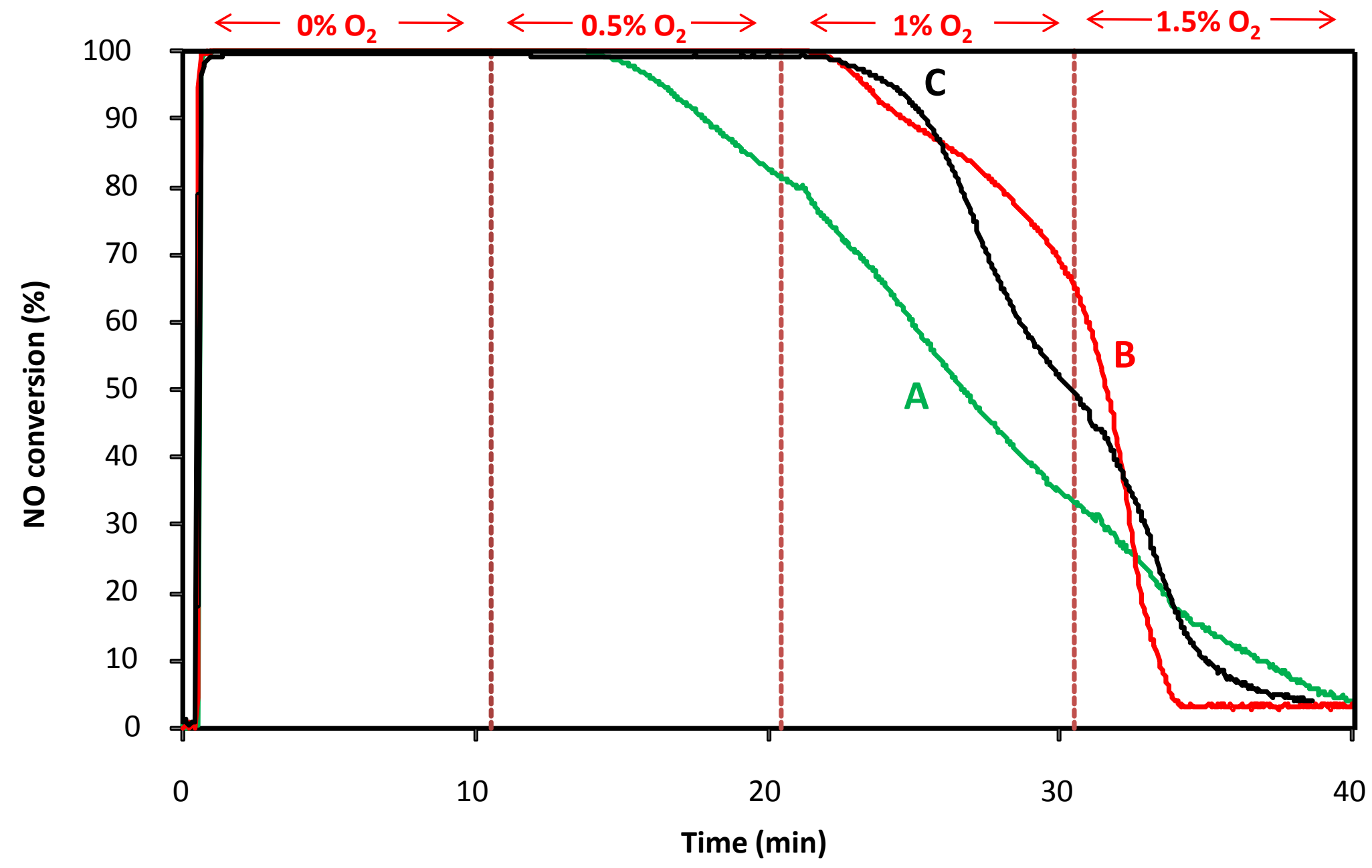




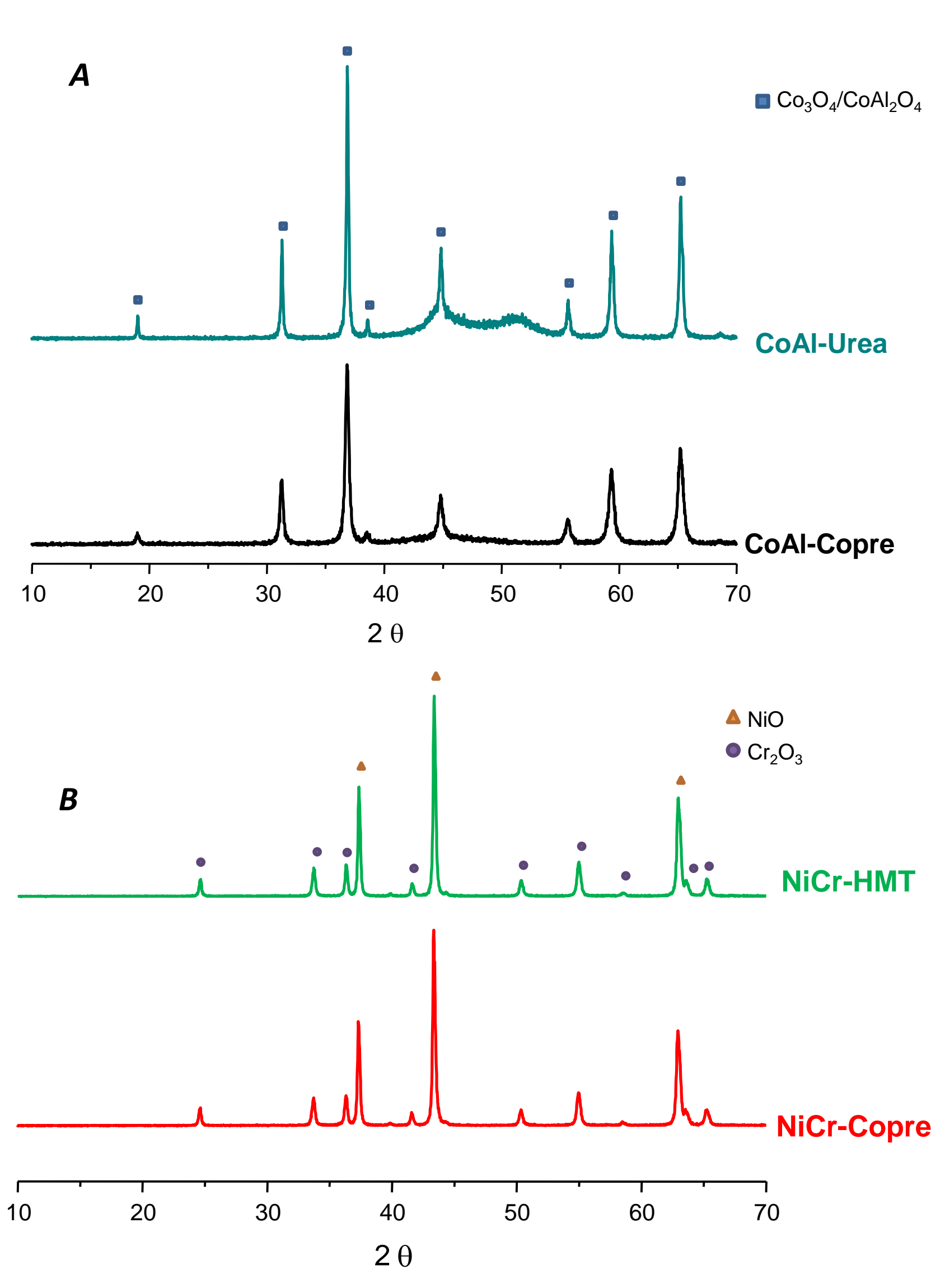

Figure 5

5

-

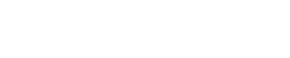

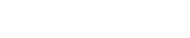

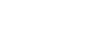




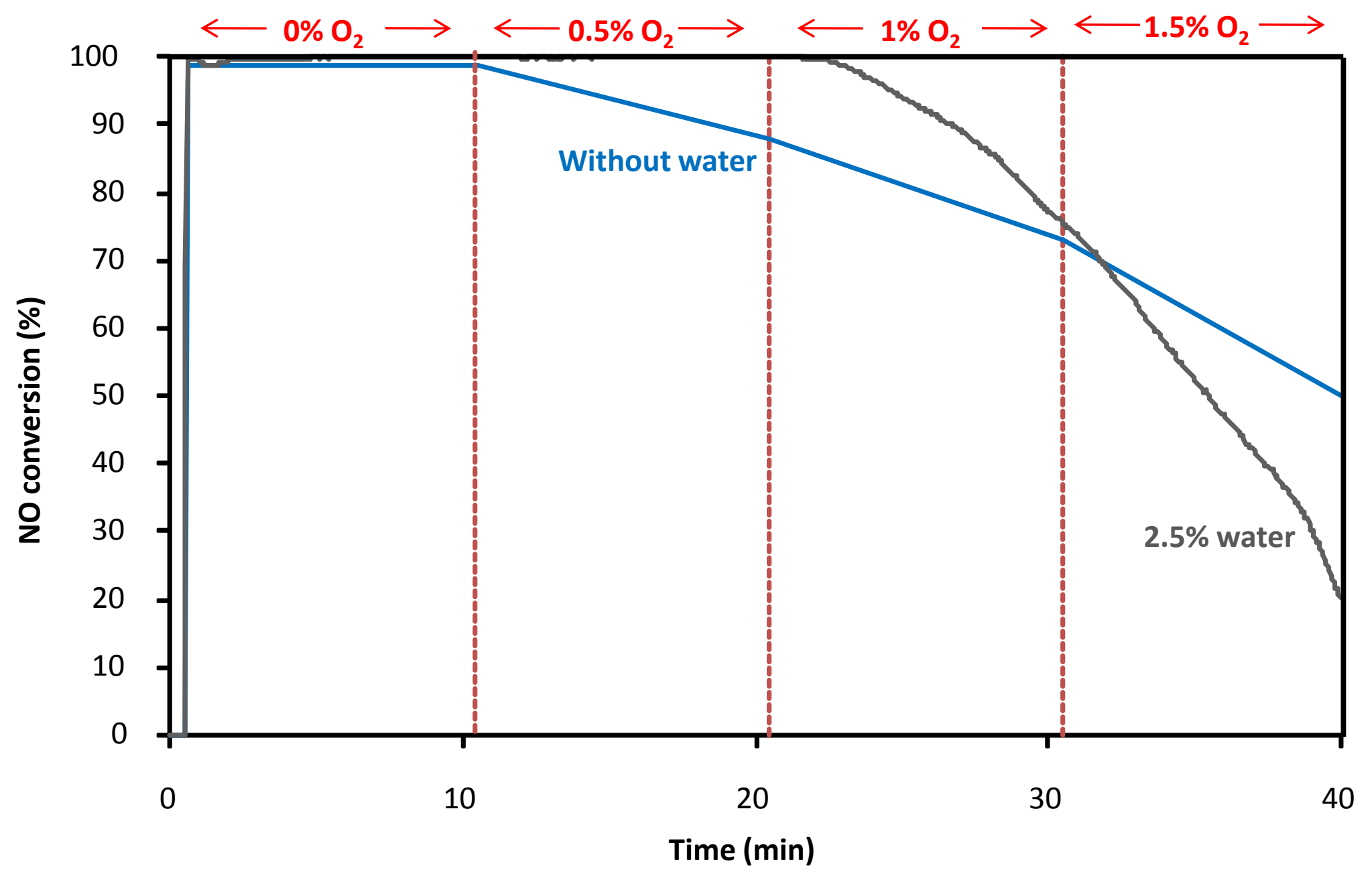

